Kelaniya Journal of Human Resource Management

Volume 09-Number 01-January 2014 \& Number 02-July 2014

\title{
Analysis of Stress on Employees' Productivity: A Study based on Air Force Officers in Sri Lanka
}

\author{
Romita Devi De Silva ${ }^{1}$ and K. K. Thilakasiri ${ }^{2}$ \\ ${ }^{1}$ Department of Management and Finance, General Sir John Kotelawala Defence \\ University, Sri Lanka \\ ${ }^{2}$ Department of Accountancy, University of Kelaniya, Sri Lanka \\ 12deviromita@yahoo.com, ${ }^{2}$ ktilakasiri@kln.ac.lk
}

\begin{abstract}
Job stress is became one of the main challenges faced by many organisations. It is usually occurs when employees cannot cope with pressure or tension of assigned task. It can be considered as one of the factors which influence the work behavior of employees. Work behavior of an employee can be affected due to stress either in positive or negative way. Negative impact of employees' work behavior due to stress might contribute to lower employees' productivity ultimately affecting organization performance. According to AIS (the American Institute of Stress) report, $\$ 300$ billion spend annually due to accident, absenteeism, turnover, medical, legal, insurance costs and workers' compensation as a result of job stress. The main aim of this study is to identify most significance stressor and also to analyses its effect on employees' productivity. Descriptive survey was adopted as the research design of the study. This study has been conducted based on Sri Lanka Air Force with reference to three bases. The primary data were collected through a questionnaire survey from 67 Air Force officers. The results of the study indicate that over workload (.332**), excessive responsibility (.495**), poor relationship $(.518 * *)$, meet deadline $(.494 * *)$, and harassment $(.558 * *)$ are statically significant factors in predicting the level of stress in Air Force officers. Educational level and civil status are most significant demographic factors affecting the level of stress. Finding of the study shows that there is a low positive relationship between stress and productivity.
\end{abstract}

Keywords: Job stress, Stressors, Productivity

\section{Introduction}

Nowadays, stress at the workplace is becoming one of the significant challenges faced by most of the organizations Preston 2003. It is one of the 
factors which influence the work behavior of employees. Therefore, workplace stress plays a role in employee productivity. Employees are the most valuable asset in any organization due to their main roles in the organization's effectiveness. It is necessary to pay give attention on employees stress at workplace.

\section{Background of the Study}

In modern world, job stress is become one of the vital issues at workplace where most employers does not give much attention on employees stress. Workplace stress is a considerable cost on employee work behavior. According to Nonprofit risk management consulting service (2016), workplace stress is defined as the harmful physical and emotional responses that occur when the requirements of the job do not match the capabilities, resources, or needs of the employee or volunteer'. Workplace stress usually occurs when an individual cannot cope with pressure or tension of assigned work. Some of the factors which causes stress at workplace could be: over workload, meet deadline, excessive responsibility, poor relationship with colleagues, poor relationship with management, inappropriate work system, poor management, overtime and works on holidays, harassment, give too much challenging and creative works. These factors might have possible of causing harm on employees' mental and physical fitness which might give negative impact on the employees' work behavior. Velayutham \& Chandru (2012) found that the factors which influence to distress are workload, depression, tension, and boss, abusive comment, less salary, no proper career ladder and night shift. Bashir \& Ramay (2010) found that main reasons to reduce performance of employees are workload and time constraint. As per the stress pulse survey report (2014), 64\% of employees have high level of stress with extreme fatigue, $31 \%$ of employees have manageable stress level while only $5 \%$ of employees have low stress level. Hence, stress is become one of the common issue in modern life as majority of us spend most of our time at workplace. Work behavior of an employee can be affected due to stress either in positive or negative way. When employees are in stress, their productivity level may low or high as compare to normal production rate (. When employees are unproductive, they take longer time to complete the task which is cost to the employer. Employees' productivity directly affects an organizations' performance in terms of growth and profitability. The purpose 
of this study is to examine how workplace stress relates on employees' productivity at workplace.

\section{Effects of Stress}

Stress can have various effects on the employees depend on the individual's behavior. Many employees are experiencing of distress at workplace. Distress occurs when the level of stress is either too high or too low. When distress arises, individual mind and body begins to respond negatively which lead anxiety, depression and physical illnesses. It is an unpleasant feeling that may cause problem to the individual. Goldberg (2014) stated, stress becomes distress when an individual faces continuous challenges without relief between challenges. Reviewer also mentioned mentioned that 75 to $90 \%$ of individual visit doctor for stress related ailments and complaints. Therefore, Bashir \& Ramay (2010) mentioned that job stress significantly reduce the performance of an individual.

\section{Research Problem}

Stress at the workplace becomes a common factor in most of organizations especially in the Military organization et al (N.D). Menze (2006) mentioned that high level of stress at workplace resulted in low productivity, increased absenteeism and turnover and also lead with other problems as alcoholism, drug abuse, and hypertension. Negative stress causes mental restlessness, mental disturbance and loss of self-balance which is harmful to the individual and, as a result, drives a change in an individual's behavior. Change in negative behavior of an individual at workplace effect on their productivity as well as to the organization's performance. According to AIS (the American Institute of Stress), job stress is costly for U.S. Industry with price tag over $\$ 300$ billion annually due to accident, absenteeism, turnover, medical, legal, insurance costs and workers' compensation. To overcome those situations, it is needed to identify the causes of stress at workplace and its influence on employee productivity. As per the observation of researcher, Military officers are more stressful because of the nature of organization and type of their work. Therefore, problem statement of the study is to analyze "how stress effect on the productivity" of an individual at workplace. This research investigates the causes of stress at workplace and the relationship between stress and productivity. 


\section{Aim and Objectives of the Research}

The aim of this research is to understand the causes of stress at workplace and how it influences on the productivity of Air force officers in Sri Lanka. The main objective of the study is to determine the significant stressor factors and also to analyze how stress effect on employees' productivity among the selected Air force officers. In order to achieve the main objective, researcher has developed four specific objectives.

i. To evaluate the level of stress among the Air force officers

ii. To investigate the most significance factors which increase the level of stress of an Air force officer

iii. To determine the relationship between stress and productivity among the Air Force officers

\section{Significance of the study}

Air force job can be considered as one of the most stressful occupations. Military Air force officers perform their duty at any time, at any risk situation based on the demand. Many researchers highlighted that working under continuously stressful conditions leads to the employee dissatisfaction, low productivity, health issue, high turnover and absenteeism. Individual performance takes an important role in the effectiveness of the organization performance. As a result, it is needed to consider wellbeing of employees in an organization. Employer or management need to give attention on stress factors in an organization and how it affects to employee productivity. Identifying stressors among the Air Force officers and its effect to productivity might provide opportunity to shape the positive organization culture by adopting policies on stress management which lead to improve organization performance.

\section{Literature Review}

\subsection{Over Workload Pressure}

Many research papers demonstrate that over workload pressure is one of the serious stressor at workplace. Many employees experience considerable pressure due to overload work. Due to heavy workload, employees are working for long hours, extra hours, and holidays and even in sick days. Greiner, 1998 mentioned that 'work-related stress occurs when one's job 
demands are incompatible or mismatched with the mental regulation processes, such as information processing, planning, and movement execution' (Aftab \& Javeed, 2012). Velayutham \& Chandru (2012) mentioned that work place stress occurs due to work overload, poor relations, working condition, discrimination, lack of opportunities and boredom. Authors are also added gender discrimination, sexual harassment, and the pressures of combining work and family cause stress on working women. Dhankar (2015) conclude that overload, ambiguity, pressure, confliction are responsible factors which cause stress at workplace.

\subsection{Excessive Responsibility}

Assigning excessive responsibilities to employee is also one way to increase stress level at workplace. In most of the organizations, employees are handling excessive responsibilities beyond their specialist duties. Assigning excessive responsibility may be a positive or negative stressor. Aftab \& Javeed (2012) identified the main stressors at the workplace are work beyond normal jobs range, excessive responsibilities, excessive workload than normal work, assigned excess work and force to work by supervisors, poor communication. However, Gaval \& Aisner (2012) reveal that leaders who are having higher levels of leadership responsibility have less stress compared to those with less responsibility.

\subsection{Poor Relationship}

Iqbal \& Waseem (2012) defined workplace relationships are unique interpersonal relationships with important implications for the employees and the organizations development. They further identified, the quality of relationships has important consequences for employee experiences. Employees are reluctance to come at workplace and have the feeling of constant pressure if they are not happy with supervisor or coworkers. This tension leads to negative or poor relationship at workplace. According to ERC HR Insights Blog (2013), poor relationship or too much conflict with supervisors is one of the leading sources of stress at workplace and also further mentioned that treating employees inconsistently by supervisors lead to stressful work situations. 


\subsection{Meeting Deadlines}

Deadlines are incredibly stressful at workplace. Employees are more tensed and pressured when they are closer to deadline of their work. Due to heavy workload or excessive duties and responsibilities, often most of the employees are facing the problem of meeting deadline of their work. Working under time pressure leads to cause errors of work, low quality of work and accompanied harmful to employees' health by physiological, psychological, and behavioral. Rao \& Pradhan (2007) mentioned that deadline relating to stress at work is mainly due to lack of clarity in the work environment. Researchers also further mention that cultivating the specific knowledge to work with deadlines could help to minimized stress cause by meet deadline. Ahmed \& Ramzan (2013) mentioned that problems occur at workplace when the sources of pressure become too frequent and too much without time to recover and cope with.

\subsection{Harassments}

David H. Greenberg defined workplace harassment is "any actions by one employee toward another which is unwelcome and led to an employee having difficulty doing his or her work". Harassment at workplace may involve ignoring or excluding employee, misbehavior, spreading malicious rumors or gossip of that person, humiliating, assigns unachievable or meaningless tasks, purposefully pressurize or torture, constantly undervaluing someone's work performance, criticizing on someone's performance, discouraging someone's applicable ideas. These bullying lead a hostile work environment. Gender, age, religion, ethnicity, race, genetic information and sexual orientation are some of the considerable factors of workplace harassment. Rana \& Munir (2011) identified some of the causes of stress at workplace are inability to meet the demands of the job, excessive work pressure, to meet deadlines, to be more creative, working overtime, work on holidays, not being promoted, job rotation, harassment.

\subsection{Stress and Productivity}

The effect of stress at workplace may be positive or negative. Negative stress might interference the ability on employees' productivity. It can lead to increased absenteeism, employees turnover, cost to organisation and health hazards. Halkos and Bousinakis (2008) revealed that increased stress leads to 
reduced productivity of an employee. Ali \& Abid (2015) also revealed that work stress is one of the main reasons which employees decline in their performance. Naqvi, Khan \& et.al (2013) found that increased work stress lead to decreased employee productivity. According to stress pulse survey report (2014), 42\% lose 15 - 30 minutes per day in productivity due to stress, $35 \%$ lose 1 hour or more per day in productivity due to stress while $24 \%$ reported productivity is unaffected by stress.

\section{Methodology}

\subsection{Conceptual Framework}

The conceptual framework (Figure 3.1) of the study is developed based on the literature review and researcher observation. In this framework, stress is considered as intervening variables which becomes the function of independent variables. Here, employee productivity is considered as a dependent variable and over workload pressure, excessive responsibility, poor relationship, meet deadline and harassment are considered as important stressor factors at workplace as independent variables.

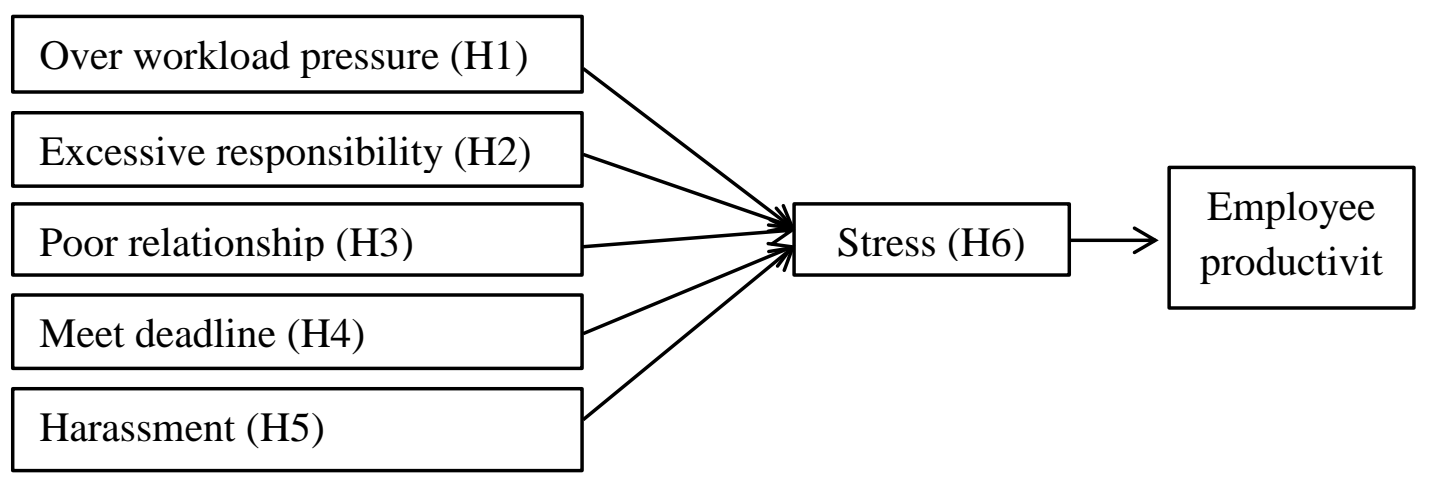

Figure 01: Conceptual framework of the study 


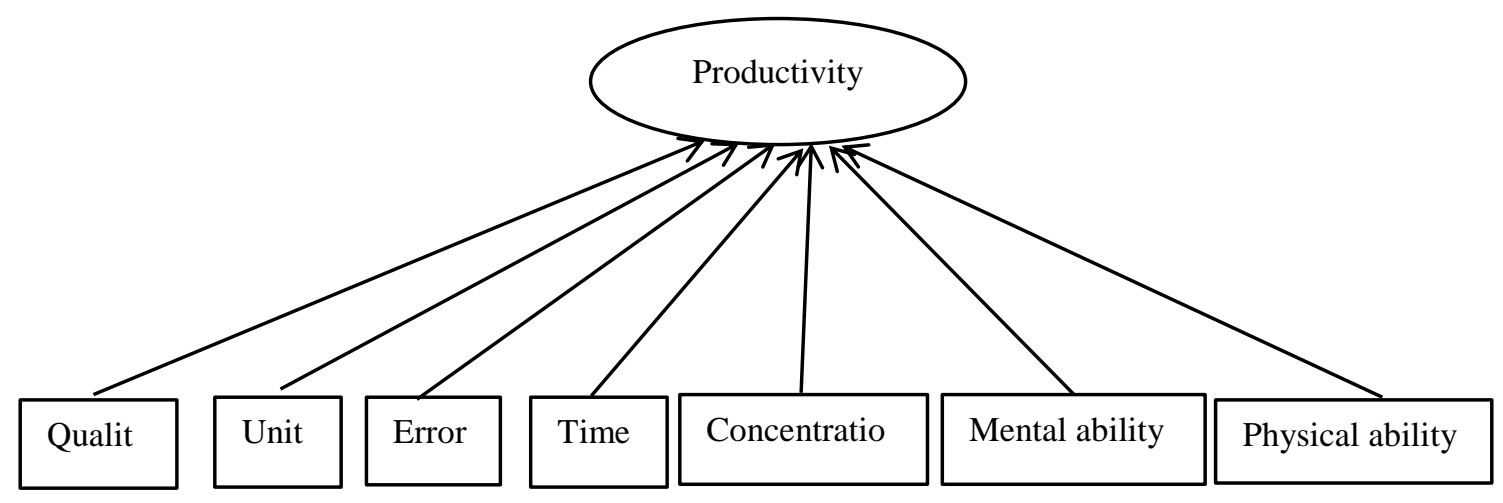

Figure 02: Yardstick of productivity

\subsection{Hypotheses of the Study}

The following hypotheses were constructed based on the conceptual framework shows in the figure 01 .

$\mathrm{H}_{1}$ : There is a significant relationship between over workload and stress

$\mathrm{H}_{2}$ : There is a significant relationship between excessive responsibility and stress

$\mathrm{H}_{3}$ : There is a significant relationship between poor relationship and stress

$\mathrm{H}_{4}$ : There is a significant relationship between meet deadline and stress

$\mathrm{H}_{5}$ : There is a significant relationship between harassment and stress

$\mathrm{H}_{6}$ : There is a significant relationship between stress and employee productivity

\subsection{Sample and Sampling}

The unit of analysis for this study is based on individual officer working in the Sri Lanka Air force. This study is based on three selected Air force bases. Researcher used simple random sampling method in order to select the target sample. Expected sample of a total of 75 officers have be selected from the identified bases. Twenty five middle level officers (Squadron leaders and Flight Lieutenants) have been selected from each base. 


\subsection{Data Collection}

The main data collection tool is questionnaire. The questionnaires were distributed personally to the middle level officers of the selected bases. Question number 1 to 8 consists of demographic variables such as gender, civil status, Age, rank, educational qualification, tenure at present organization in order to obtain basic details of respondents. Question number 9 measured the most stressful aspects among the Air force officers. Question 10 measured the overall level of stress at present organization. Question number 11 measured level of stress on stressor and 12 measured the stress reaction. Question number 13 measured the level of productivity when work under stress by using 12 items. The opinions of the respondents were gathered by using 5-point Likert scale. Secondary data necessary for the research has been gathered through the related journals, books, newspapers, magazine and online articles. A comprehensive literature survey was carried out for different aspects of the study.

\subsection{Data Analysis Tools}

The structured questionnaire is designed to collect data mainly using five point Likert scale. Collected data and hypotheses of the study are presented, tested and analyzed based on the statistical measures, diagrams and tables. SPSS (Statistical Package for the Social Sciences) software was utilized to analyze the collected primary data. Correlation analysis was used to identify the responsible factors of stress and their influence on productivity.

\subsection{Reliability Test}

Cronbach Alpha value is calculated based on the feedback of 12 items that directly affect the stress levels of employees. The high value of the Cronbach Alpha 0.796 which is almost 0.80 suggests that the questionnaire used for collecting data on stress level about stressor factors is highly reliable. It indicates that a high level of internal consistency of the questionnaire used.

\section{Data Analysis and Presentation}

\subsection{Sample Composition}

Researcher has received only 67 questionnaires out of 75 questionnaires. Analysis of this research is based on the 67 respondents. Only 06 percent are 
female respondents where 94 percent are male respondents in this study. Majority (43\%) of respondent are in between 31 to 35 ages. Out of 67 respondents 32 respondents are graduates and 11 respondents are post graduates. There are only 10 respondents are diploma and 14 respondents are secondary.

\subsection{Overall Stress Level}

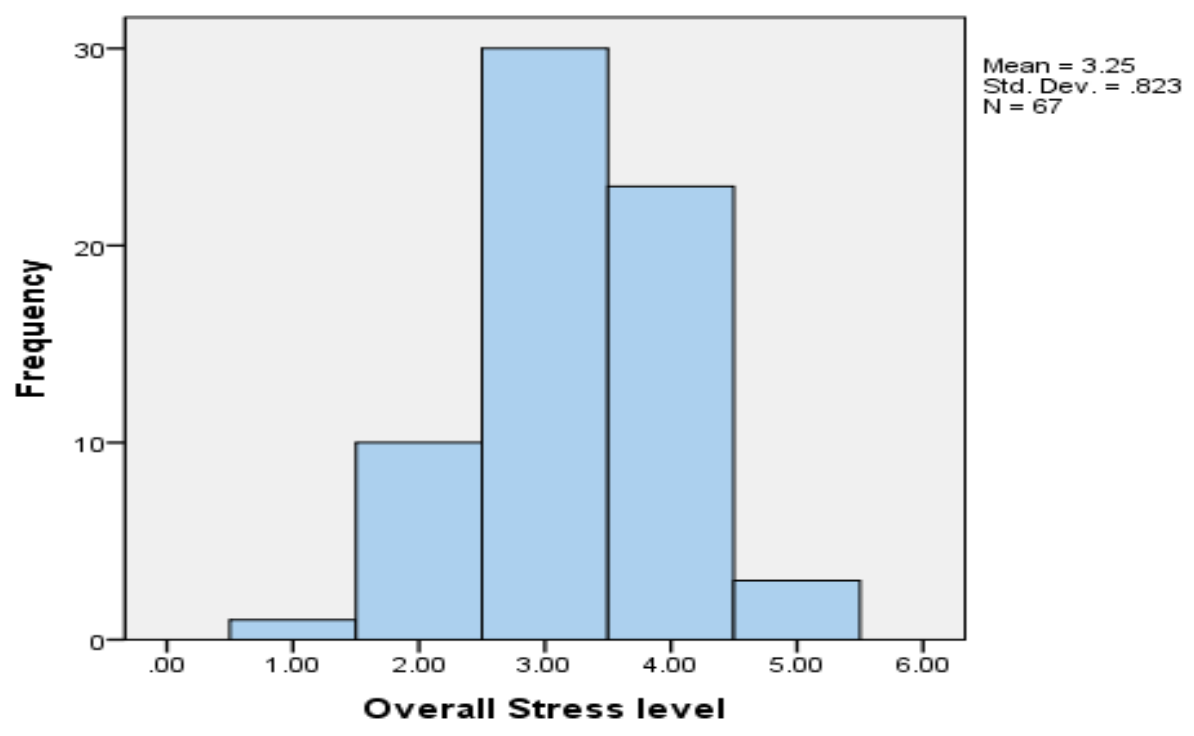

\section{Figure 03: Overall stress level}

As per the result of data in figure 4.1 , only $1.5 \%$ of respondents stated that stress level among the Air Force officer is very low, 15\% stated low and 43\% stated moderate. However, $35.5 \%$ of the respondents stated that stress level is high and also 5\% have mentioned that stress level is very high. The mean value of 3.25 which fall in moderate (range 2.60 - 3.39) indicates that stress level among the Air Force officers is moderate. 


\subsection{Most Stressful Aspect}

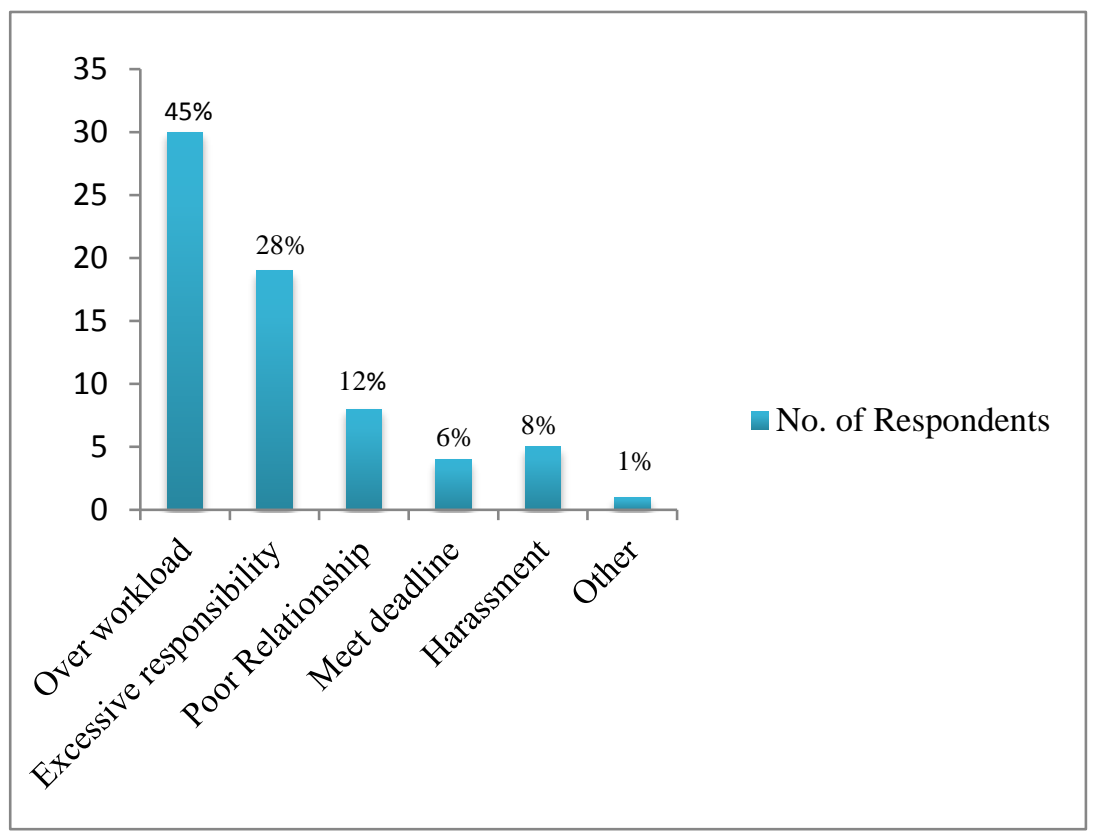

As per the result, majority (45\%) respondents stated that over workload is most stressful aspect. 19 (28\%) respondents mentioned that excessive responsibility is most stressful aspect. However, $8(12 \%)$ stated that poor relationship is most stressful aspect. Only $4(6 \%)$ respondents stated that meet deadline is most stressful aspect and also only $5(8 \%)$ respondents mentioned that harassment is most stressful aspect. As per the graph, it indicates that over workload is most stressful aspect of Air Force officers follow by excessive responsibility. 


\subsection{Hypotheses Testing}

\subsubsection{Relationship between Work Overload and Stress}

Table 01: Correlation between stress and over workload

\begin{tabular}{|l|c|c|}
\hline & STR & OWL \\
\hline Pearson Correlation & 1 & $.332^{* *}$ \\
Sig. (2-tailed) & & .006 \\
$\mathrm{~N}$ & 67 & 67 \\
\hline Pearson Correlation & $.332^{* *}$ & 1 \\
Sig. (2-tailed) & .006 & \\
$\mathrm{~N}$ & 67 & 67 \\
\hline
\end{tabular}

**. Correlation is significant at the 0.01 level (2-tailed).

Table 01 gives the result of correlation between over workload (OWL) and stress (STR). The model in correlation table 01, suggests that correlation coefficient (r) is equal to 0.332 indicating there is a weak positive relationship between over workload and stress. $\mathrm{P}$ value for this correlation coefficient is 0.006 which is $<0.01$ significant value. It meant that there is statistically significant between over workload and stress. Hence, hypothesis has been accepted.

\subsubsection{Relationship between Stress and Excessive Responsibility}

Table 02: Correlation between Stress and Excessive Responsibility

\begin{tabular}{|l|c|c|}
\hline & STS & ERS \\
\hline Pearson Correlation & 1 & $.495^{* *}$ \\
Sig. (2-tailed) & & .000 \\
$\mathrm{~N}$ & 67 & 67 \\
\hline Pearson Correlation & $.495^{* *}$ & 1 \\
Sig. (2-tailed) & .000 & \\
$\mathrm{~N}$ & 67 & 67 \\
\hline
\end{tabular}

**. Correlation is significant at the 0.01 level (2-tailed). 
Table 02 shows the correlation between stress (STS) and excessive responsibility (ERS). As per table, correlation coefficient (r) is .495 representing there is a positive relation between excess responsibility and stress. By looking the 'p' value .000 of this correlation coefficient, there is a statistically significant relationship between stress and excessive responsibility. Hence, hypothesis has been accepted.

\subsubsection{Relationship between Stress and Poor Relationship}

Table 03: Correlation between Stress and Poor Relationship

\begin{tabular}{|l|l|l|}
\hline & STS & PRT \\
\hline Pearson Correlation & 1 & $.518^{* *}$ \\
Sig. (2-tailed) & & .000 \\
$\mathrm{~N}$ & 67 & 67 \\
\hline Pearson Correlation & $.518^{* *}$ & 1 \\
Sig. (2-tailed) & .000 & \\
$\mathrm{~N}$ & 67 & 72 \\
\hline
\end{tabular}

**. Correlation is significant at the 0.01 level (2-tailed).

As per table 03, there is a strong positive relationship between stress (STS) and poor relationship (PRT) as ' $r$ ' value is equal to .518 . P value of .000 also shows that there is a significant relationship between stress and poor relationship. It meant that increase in one variable will lead to increase other variable. Therefore, hypothesis has been accepted.

As per table 04, the correlation between stress (STS) and meet deadline (DTP) is .494 and $p$ value is .000 which is significant at 0.05 level. Hence, there is a positive relationship between stress and meet deadline and it is statistically significant. Hypothesis has been accepted. 


\subsubsection{Relationship between Stress and Meeting Deadlines}

Table 04: Correlation between Stress and Meeting Deadlines

\begin{tabular}{|l|c|c|}
\hline & STS & DTP \\
\hline Pearson Correlation & 1 & $.494^{* *}$ \\
Sig. (2-tailed) & & .000 \\
N & 67 & 67 \\
\hline Pearson Correlation & $.494^{* *}$ & 1 \\
Sig. (2-tailed) & .000 & \\
N & 67 & 72 \\
\hline
\end{tabular}

**. Correlation is significant at the 0.01 level (2-tailed).

\subsubsection{Relationship between Stress and Harassment}

Table 05: Correlation between Stress and Harassment

\begin{tabular}{|l|c|c|}
\hline & STS & HSM \\
\hline Pearson Correlation & 1 & $.558^{* *}$ \\
Sig. (2-tailed) & & .000 \\
$\mathrm{~N}$ & 67 & 67 \\
\hline Pearson Correlation & $.558^{* *}$ & 1 \\
Sig. (2-tailed) & .000 & \\
$\mathrm{~N}$ & 67 & 72 \\
\hline
\end{tabular}

**. Correlation is significant at the 0.01 level (2-tailed).

Table 05 represents the correlation between stress (STS) and harassment (HSM). As per table, correlation coefficient (r) is .558 which shows that there is a strong positive relationship between stress and harassment. It meant that when one variable is increase or decrease other variable also will increase or decrease. $\mathrm{P}$ value of correlation coefficient (r) is .000 which is significant at 0.05 . It concludes that there is a significant relationship between stress and harassment. Therefore, hypothesis has been proved. 


\subsubsection{Relationship between Stress and Employee Productivity}

Table 06: Correlation between Stress and Productivity

\begin{tabular}{|cl|c|c|}
\hline & & PRO & STR \\
\hline PRO & Pearson Correlation & 1 & .023 \\
& Sig. (2-tailed) & & .851 \\
& $\mathrm{~N}$ & 67 & 67 \\
\hline STR & Pearson Correlation & .023 & 1 \\
& Sig. (2-tailed) & .851 & \\
$\mathrm{~N}$ & 67 & 67 \\
\hline
\end{tabular}

Table 06 represents the correlation between stress (STR) and productivity (PRO). According to this table, the correlation of coefficient is 0.023 which meant that there is low positive relationship between stress and productivity. The significant level of $\mathrm{p}$ value is equal to 0.851 which is greater than 0.01 . Hence, there is no statistically significant relationship between productivity and stress. Therefore, hypothesis has been rejected.

\section{Findings and Discussion}

Based on the responses, the finding revealed that the overall stress level among the Air force officers is moderate. The mean value 3.25 is fall in the range of moderate. Forty five percent of respondents mentioned that the most stressful aspect is over workload. Twenty eight percent and $12 \%$ of respondents also revealed that excessive responsibility and poor relationship are most stressful aspects. However, only $6 \%$ and $8 \%$ of respondents revealed that meet deadline and harassment are most stressful aspects. Hence, it can state that most stressful aspects among the Air Force officer are over workload and excessive responsibility. Based on the result of hypothesis testing, there is a low positive relationship between stress and productivity. It also shows that there is no statistically significant relationship between stress and productivity. Hence, stress is not the main important factor on the productivity of Air Force officers. 
Table 07: Correlations

\begin{tabular}{|l|l|l|l|l|l|}
\hline & \multicolumn{1}{|c|}{$\begin{array}{c}\text { Over } \\
\text { Workload }\end{array}$} & $\begin{array}{c}\text { Excessive } \\
\text { Responsibility }\end{array}$ & \multicolumn{1}{c|}{$\begin{array}{c}\text { Poor } \\
\text { Relationship }\end{array}$} & $\begin{array}{c}\text { Meet } \\
\text { Deadline }\end{array}$ & \multicolumn{1}{c|}{ Harassment } \\
\hline Stress & $.332^{* *}$ & $.495^{* *}$ & $.518^{* *}$ & $.494^{* *}$ & $.558^{* *}$ \\
$\begin{array}{l}\text { Pearson Correlation } \\
\text { Sig. (2-tailed) }\end{array}$ & .006 & 000 & .000 & .000 & .000 \\
N & 67 & 67 & 67 & 67 & 67 \\
\hline
\end{tabular}

Correlation is significant at 0.01 level

\section{Table 08: Summary of Hypotheses Testing Results}

\begin{tabular}{|l|l|l|}
\hline \multicolumn{1}{|c|}{ Hypothesis } & \multicolumn{1}{|c|}{ Result } & \multicolumn{1}{|c|}{ Relationship } \\
\hline H1: There is a significant relationship between over workload and stress & Supported & Low positive \\
\hline H2: There is a significant relationship between excessive responsibility and stress & Supported & Moderate positive \\
\hline H3: There is a significant relationship between poor relationship and stress & Supported & Strong positive \\
\hline H4:There is a significant relationship between meet deadline and stress & Supported & Moderate positive \\
\hline H5: There is a significant relationship between harassment and stress & Supported & Strong positive \\
\hline H6: There is a significant relationship between stress and productivity & Not Supported & Low positive \\
\hline
\end{tabular}




\section{Conclusion}

Workplace stress is become one of the vital concerns for any kind of organization nowadays. Based on the result of the survey, educational level and civil status are most significant demographic factors affecting the level of stress among the Sri Lanka Air Force officers. Majority of the respondents indicate that over workload is the most stressful aspect of Air force officers follow by excessive responsibility, poor relationship, and harassment and meet deadline. It also demonstrates that workload, excessive responsibility, poor relationship, meet deadline and harassment are significant factors in predicting the level of stress of Sri Lanka Air Force officers. There is a strong positive relationship between poor relationship, harassment and stress. However, overall stress level among the Air Force officers is moderate. It also revealed that majority of the officers consult their supervisor when they are in stress. However, some of the officers are difficult to control their anger when they are in stress. Mean value of 3.42 shows that more than $50 \%$ of respondents get upset when they are in stress. This study found that there is low positive relationship between stress and productivity. Stress is not the significant factor of employee productivity. It also revealed that when employees are in stress, their productivity level is not so high and not so low it means 'moderate'.

\section{References}

Aftab, H \& Javeed, A. (2012) The Impact of Job Stress on the Counterproductive Work Behavior (CWB): A Case Study from the financial Sector of Pakistan. Interdisciplinary journal of contemporary research in business. Vol. 4, No. 7.

Ahmed, A. \& Ramzan, M. (2013) Effects of Job Stress on Employees Job Performance. IOSR Journal of Business and Management. Vol. 11, No. 6

Ali, M. \& Abid, N. (2015). Impact of stress antecedents on work stress and employees performance, International Journal of Business and Management Invention. Vol. 4 No. 11 
Bashir, U \& Ramay, MS (2010). Impact of Stress on Employees Job Performance: A Study on Banking Sector of Pakistan. International Journal of Marketing Studies. Vol 2. No.1

Danielle Boyd (2016) Financial Stress Coping Guide for seniors, accessed on 01.10.2016 from http://www.stress.org/2016/09/

Dhankar, S. (2015) Occupational stress in banking sector. International Journal of Applied Research. Vol.1, No. 8

Blog E.H.I. (2013). 5 causes \& Cures of workplaces stress. Available from: http://www.yourerc.com/blog/post/5-Causes-Cures-of-WorkplaceStress.aspx

Gavel, D. and Aisner, J. (2012) Laboratory Study of Leaders Shows Surprising Result: As Responsibility Increases, Stress Decreases. Available from: http://www.hbs.edu/news

Greenberg, DH. Workplace Harassment. Available from: http://www.discriminationattorney.com/workplace-harassment.html

Goldberg, J (2014). How Does Stress Affect Health. Available from: http://www.webmd.com/balance/stress-management/effects-of-stresson-your-body

Halkos, G. and Bousinakis, D (2008). The influence of stress and satisfaction on productivity. International Journal of Productivity and Performance Management. Vol. 59. No.5

Halkos, G. and Bousinakis, D (2010). The effect of stress and satisfaction on productivity. International Journal of Productivity and Performance Management. Vol. 59. No.5

Health and Safefy Executive (HSE), what is stress? Available from: http://www.hse.gov.uk/stress/furtheradvice/whatisstress.htm

Iqbal, M \& Waseem, A. (2012) Impact of Job Stress on Job Satisfaction among Air Traffic Controllers of Civil Aviation Authority. International Journal of Human Resource Studies. Vol. 2, No. 2 
Karen, H (2014), Workplace Stress Leads to Less Productive Employees, web Article, Accessed on 2016.09.30.

MANNING D. AND PRESTON A. (2003), Organizational Stress: Focusing on Ways to Minimize Distress, CUPA-HR Journal, summer, Vol. 54 No. 2.

Naqvi, SM., Khan, MA. Kant, AQ.and Khan, SN. (2013). Job Stress and Employees' Productivity: Case of Azad Kashmir Public Health Sector. Interdisciplinary journal of contemporary research in business.

Nonprofit risk management consulting service (2016). Tackling Stress Improves Morale, Productivity and Safety. Workplace Stress

Rana, B. \& Munir, K. (2011) Impact of stressors on the performance of employees. MPRA Paper No. 32729. Available from: http://mpra.ub.uni-muenchen.de/32729/

Rao, A and Pradhan, N. (2007) Perceived Work Deadlines: The Influence of Personality among Software Personnel. Journal of the Indian Academy of Applied Psychology. Vol 33, No. 2

Ramay, MS (2010). Impact of Stress on Employees Job Performance

A Study on Banking Sector of Pakistan. International Journal of Marketing Studies. Vol 2. No.1

Ruddock, V. What Is Positive Stress? Available from http://stress.lovetoknow.com/about-stress/what-is-positive-stress

Sauter, SL, Joseph J. Hurrell Jr., Lawrence R. Murphy and Lennart Levi (N.D.), Psychological and organizational factors, work place health and safety information, $4^{\text {th }}$ Edition, International Labor Office . Accessed on 30.09.2016 from http://www.ilocis.org/en/default.html 
Kelaniya Journal of Human Resource Management

Volume 09-Number 01-January 2014 \& Number 02-July 2014

Stress Pulse survey (Nov.12, 2014). High Stress Has Employees Seeking Both Wellness and Employee Assistance Program Help. Available from: http://www.compsych.com/press-room/press-releases2014/818-nov-12-2014.

Teak, O J. (2015) Managing stress in project management. Available from: http://www.projecttimes.com

Velayutham, M. and Chandru, D. (2012) An Empirical study on Job Stress and its impact on health workers in Private Hospitals.

Interdisciplinary journal of contemporary research in business. Vol. 4, No.7. 